\section{Effect of Silicone Rubber-Lead (SR-Pb) Thickness on Dose Reduction and Image Quality as Gonad Shield}

\author{
Zahroh F.,2®, Anam C. ${ }^{3}$, Sutanto H. ${ }^{3,4 * \odot}$, Irdawati Y.,2, Arifin \\ Z. ${ }^{1}$, Kartikasari Y. ${ }^{5}$
}

\begin{abstract}
Background: Some organs in the body are sensitive to radiation such as eyes, breast, and gonads. Protection of sensitive organs against radiation is necessary. Recently, many sensitive organ shields have been developed from different materials.

Objective: The aim of this study is to evaluate the dose reduction and image quality from implementation of Silicone Rubber-Lead (SR-Pb) as an alternative gonad shield in digital radiography (DR).

Material and Methods: In this experimental study, the SR-Pb gonad shields with various thicknesses of $2,4,6,8$, and $10 \mathrm{~mm}$ were synthesized. This study used the $\mathrm{Pb}$ percentage of $5 \mathrm{wt} \%$. An anthropomorphic phantom was used in abdomen plain examinations. The results obtained from the use of the $\mathrm{SR}-\mathrm{Pb}$ was compared with standard gonad shield, i.e. lead apron. To measure the dose reduction, the Piranha detector was used. The image quality assessment was evaluated with the signalto-noise ratio (SNR) and the contrast-to-noise ratio (CNR).
\end{abstract}

Results: This study showed the dose reduction was significant for all SR-Pb thicknesses, and incrementally increased with the increase of the SR-Pb thickness. The minimum and maximum of dose reduction were $22.8 \%$ for $2 \mathrm{~mm}$ and $66.9 \%$ for $10 \mathrm{~mm}$ SR-Pb, respectively.

Conclusion: Compared to the reference image without gonad shield, the SNR and CNR do not significantly change. Hence, the SR-Pb is probably to be used as an alternative gonad shield.

Citation: Zahroh F, Anam C, Sutanto H, Irdawati Y, Arifin Z, Kartikasari Y. Effect of Silicone Rubber-Lead (SR-Pb) Thickness on Dose Reduction and Image Quality as Gonad Shield. J Biomed Phys Eng. 2020;10(6):699-706. doi: 10.31661/jbpe.v0i0.1912-1007.

\section{Keywords}

Lead; Gonads; Imaging; Radiation Protection

\section{Introduction}

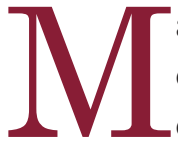

any radiological examinations are carried out with digital radiography (DR) such as for abdominal examination. The abdominal examination is frequently carried out to determine the function of secretion and excretion of both kidneys on Intravenous Pyelography (IVP) examination. According to Indonesian Basic Health Research (RISKESDAS) 2018 [1], the prevalence of chronic kidney disease increased from 2.0 to $3.8 \%$ of the Indonesian population, which caused a decline in kidney function. Chronic kidney disease is one of the leading causes of death worldwide, with a global standard-age death rate
${ }^{1} \mathrm{MSc}$, Department of

Physics, Faculty of Sci-

ences and Mathematics,

Diponegoro University,

Semarang, Indonesia

${ }^{2} \mathrm{MSc}$, Smart Mate-

rial Research Center

(SMARC), Diponegoro

University, Semarang,

Indonesia

${ }^{3} \mathrm{PhD}$, Department of

Physics, Faculty of Sci-

ences and Mathematics,

Diponegoro University,

Semarang, Indonesia

${ }^{4} \mathrm{PhD}$, Smart Material Re-

search Center (SMARC),

Diponegoro University,

Semarang, Indonesia

${ }^{5} \mathrm{MSc}$, Health Polytechnic

of Semarang, Ministry of

Health, Indonesia

*Corresponding author: H. Sutanto

Professor and Head of

Smart Material Research

Center (SMARC) Labo-

ratory of Diponegoro

University, Semarang,

Indonesia

E-mail: herisutanto@live. undip.ac.id

Received: 16 December 2019 Accepted: 12 February 2020 
increasing by $36.9 \%$ per 100.000 [2]. The IVP examination includes reproductive organs. The International Commission on Radiological Protection (ICRP) reported that human reproductive organs are very sensitive to radiation and have to be protected. The weighted factor of the gonad is 0.08 , i.e. the dose delivered to the gonad has contributing $8 \%$ of the effective whole-body dose [3]. Therefore, the radiation dose must be optimized according to the principle of as low as reasonably achievable (ALARA). One common method to reduce the radiation dose on the reproductive organs in the radiological examination is the used of the gonad shield [4]. It should be noted that the gonad shield is for reducing patient dose and not for medical workers, therefore assessment of resulted image quality is needed. It was reported that patient's gonads influence the quality of radiological imaging because they obscure anatomical information [4]. Another study reported that the gonad shield reveals image degradation [5]. Therefore, some studies suggested not to use the gonad shield [6-10].

Development of the alternative gonad shield maintaining the image quality is essential. The effectiveness of the alternative gonad shield for dose reduction depends on the constituent material, the thickness of the shield, and the energy spectrum of the beam. Various alternative gonad shields have been produced with materials of $\mathrm{Pb}$, non- $\mathrm{Pb}$, and $\mathrm{Pb}$ combinations. The gonad shield made from bismuth (Bi) was able to reduce the radiation dose received by patients by $62 \%$. However, the use of the $\mathrm{Bi}$ shield caused noisy image [11]. Organ shields from Silicone Rubber (SR)-Bismuth (Bi), SRtungsten $(\mathrm{W})$ and SR-Barium Sulfate $\left(\mathrm{BaSO}_{4}\right)$ have been reported as alternative gonad shields. At thicknesses of 1-2 mm, their radiation attenuation ratios (RAR) are $90-95 \%$ [9]. Nevertheless, the resulted image quality has not been discussed in the report [12]. Another alternative material for organ shield from SR$\mathrm{Pb}$ has been reported [13-15]. Previously, the small percentage of $\mathrm{Pb}$ from $1-5 \mathrm{wt} \%$ in the $\mathrm{SR}-\mathrm{Pb}$ has been used for reducing eye dose in the head CT examination [14]. This study aims to evaluate the effect of the gonad shield from the $\mathrm{SR}-\mathrm{Pb}$ materials as composite materials with $5 \mathrm{wt} \% \mathrm{~Pb}$ percentage with various thicknesses on radiation dose and radiographic image quality in the abdominal examination using DR. It is hoped the alternative gonad shield is able to reduce the patient's radiation while maintaining the image quality.

\section{Material and Methods}

Sample preparation, phantom position, and dose measurement

In this experimental study, the alternative gonad shield was synthesized from the $\mathrm{Pb}$ powder (Lead Acid), Silicone Rubber (RTV 52), catalyst (Bluesil catalyst), distilled water, and polyethylene glycol (Indrasari Chemical Store, Semarang, Indonesia). The gonad shield dimension was $27 \times 17 \mathrm{~cm}^{2}$ with various thicknesses of 2, 4, 6, 8 and $10 \mathrm{~mm}$. The synthesis was performed using the sol-gel method. The advantage of this method is low processing temperature and possible to cast coatings in complex shapes [16]. The synthesis steps were as follows: Firstly, the $\mathrm{Pb}$ powder was dissolved with distilled water and polyethylene glycol solvent to prevent precipitation. After that, the $\mathrm{SR}$ and $\mathrm{Pb}$ solvents were mixed for 30 $\min$. The results of mixed were sonicated for $30 \mathrm{~min}$ in an ultrasonic bath, then it was mixed again for 6 min while catalyst was added. The results of the mixture were poured into a mold that has been smeared with silicone oil and left to dry completely. Lastly, the developed shield was cut to resemble the shape of gonad shield for right and left ovaries.

The developed gonad shields were tested on the Digitaldiagnost C50 Philips Digital Radiography (Koninklijke Philips N.V., Japan) and an abdominal part of a PBU-50 anthropomorphic phantom (Kyotokagaku co., Ltd., Japan). For the radiation dose measurement, the SR- 
$\mathrm{Pb}$ was exposed with tube voltage of $77 \mathrm{kVp}$ and the tube loading was $32 \mathrm{mAs}$ based on abdominal examination. The collimator field was $40 \times 45 \mathrm{~cm}^{2}$ for anterior-posterior (AP) projection (Figure 1). This projection contributed the high absorbed dose to ovaries [17]. The Piranha detector (RTI, Sweden) was placed under the $\mathrm{SR}-\mathrm{Pb}$ filter with the source to image-receptor distance (SID) of $100 \mathrm{~cm}$ and without using automatic exposure control (AEC). The dose measurement results from the piranha detector were displayed in the Ocean software.

\section{Image quality assessment}

Image quality assessment was performed by measuring the mean pixel value (PV), the signal-to-noise ratio (SNR) and contrast-to-

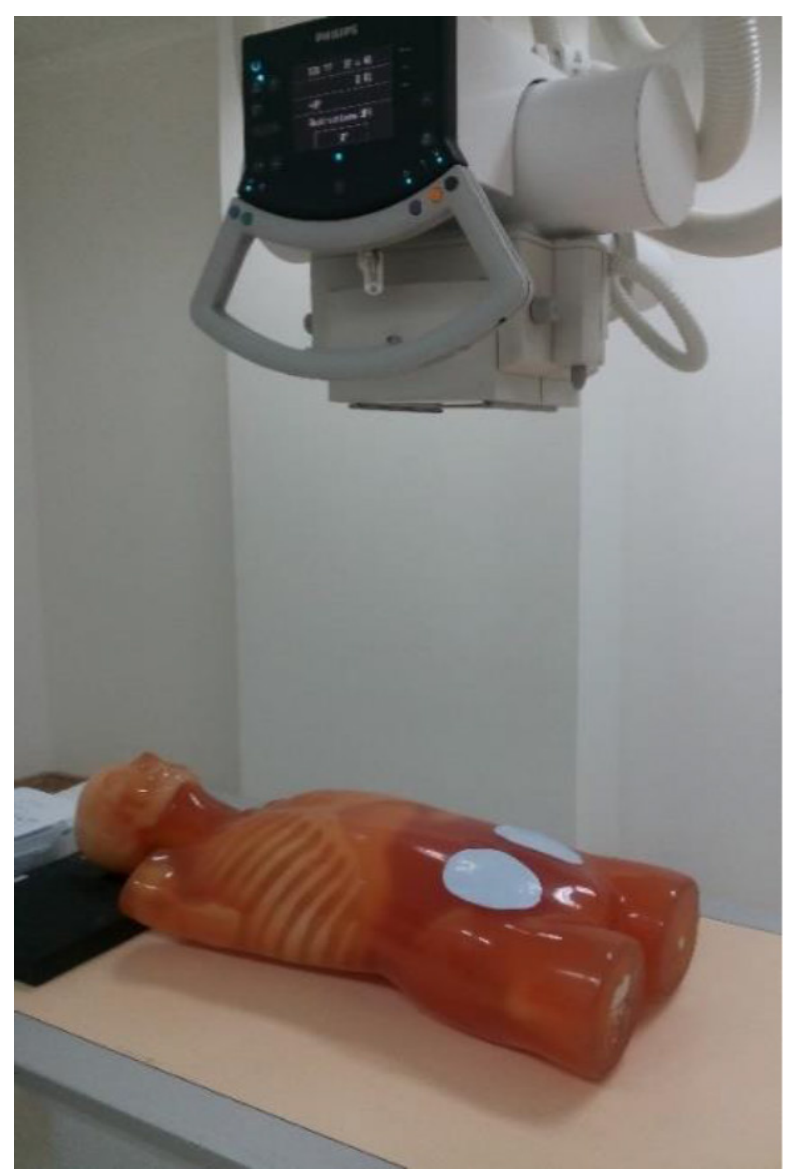

Figure 1: Research setting using a PBU-50 anthropomorphic phantom for anterior-posterior projection noise ratio (CNR). The five-circular regions of interests (ROIs) were drawn on the abdominal image (Figure 2). The background ROI was selected in areas that were considered uniform and did not overlap with other organs (Figure 2 ). The four ROIs were located at the left and right regions [18]. The SNR was calculated as comparison between PV and the standard deviation of the background ROI (the fifth circular region). The CNR was calculated as comparison between different mean PVs of four ROIs and the root square of the mean standard deviation of pixel values at four ROIs and a ROI of background [19-22].

\section{Results}

\section{Radiation dose}

The radiation doses for various SR-Pb thicknesses are shown in Figure 3. The radiation dose decreased with the increasing thickness of the SR-Pb. The percentage of the decreasing radiation dose was $22.8 \%$ for $2 \mathrm{~mm}$ SR$\mathrm{Pb}, 42.3 \%$ for $4 \mathrm{~mm} \mathrm{SR}-\mathrm{Pb}, 51.4 \%$ for $6 \mathrm{~mm}$ $\mathrm{SR}-\mathrm{Pb}, 55.3 \%$ for $8 \mathrm{~mm} \mathrm{SR}-\mathrm{Pb}$, and $66.9 \%$ for $10 \mathrm{~mm}$. The dose reduction due to the use of the lead gonad shield $(0.5 \mathrm{~mm})$ was greater, i.e. $89.4 \%$.

\section{Image Quality}

The resulted images from the use of the SR$\mathrm{Pb}$ and lead gonad shield are shown in Figure 4. It shows that the use of lead gonad shield totally blocks the image at organs that were protected. In contrary, the use of the $6 \mathrm{~mm}$ SR-Pb makes the image clearer and the image quality is relatively maintained. The parameters of image quality assessment were obtained from the ROIs of the abdominal image using the ImageJ software (National Institute of Health, Bethesda, MD), such as PV, noise, and different organ-background pixel value for measuring SNR and CNR. Figures 5a, b and c show the mean PV of ROIs (right and left ovaries), different organ-background pixel and noise values. It can be seen that the noise increases 


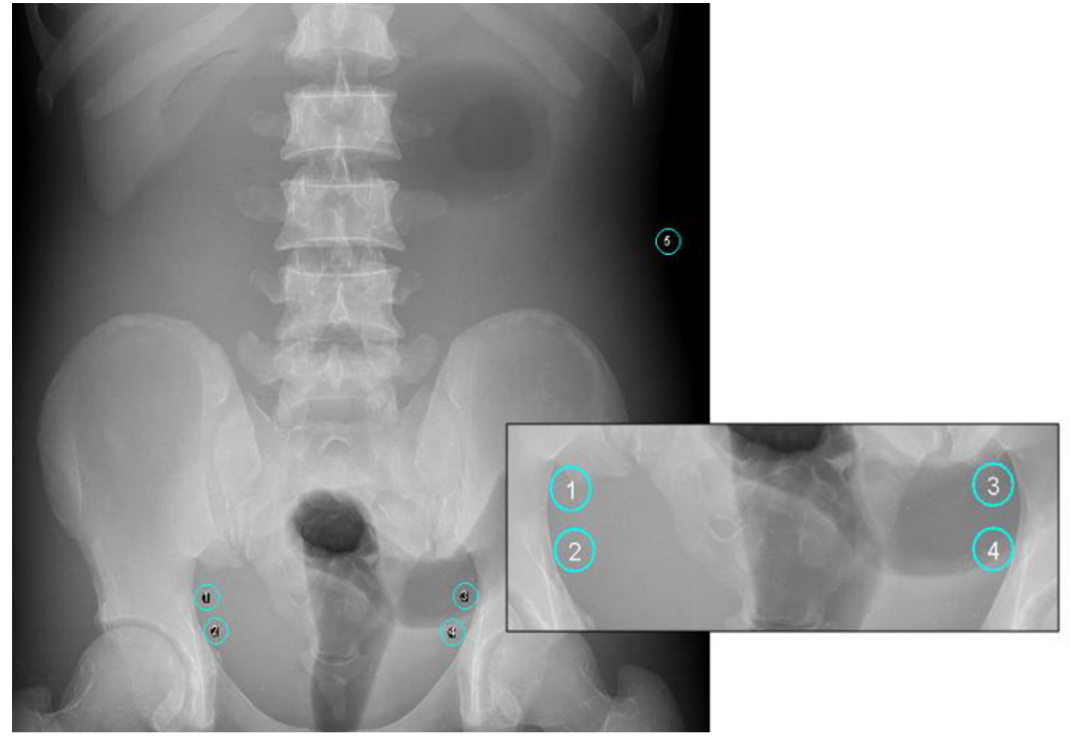

Figure 2: Regions of interests (ROIs) positions for evaluation of the Silicone Rubber-Lead (SR-Pb) gonad shield in the abdominal image. The ROls were placed at the left and right ovaries (represented by ROI number 1, 2, 3, and 4). The fifth ROI was for background area.

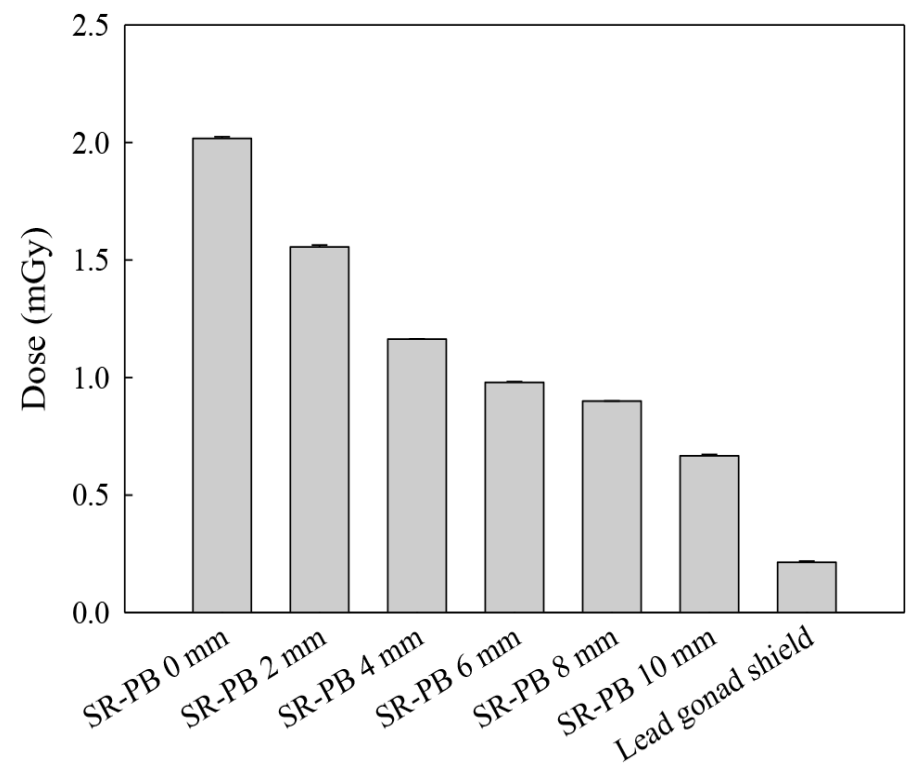

Figure 3: The radiation dose of the Silicone Rubber-Lead (SR-Pb) for various thicknesses and lead gonad shield.

with the incremental thickness of the SR-Pb. However, the lead gonad shield provides significantly higher mean PV, different organbackground pixel value and noise value.

The percentage of the increasing mean PV was about $8 \%$ for the right ovary, and $5 \%$ for the left ovary. The percentage of the increasing different organ-background pixel value was about $8 \%$ for the right ovary, and $4 \%$ for the left ovary (Figures 5a, b and c). Figure 


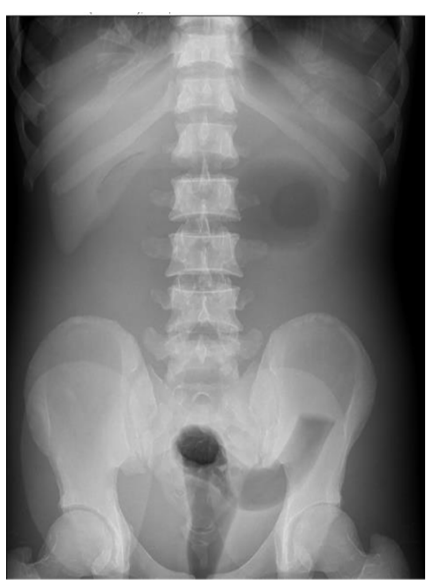

(a)

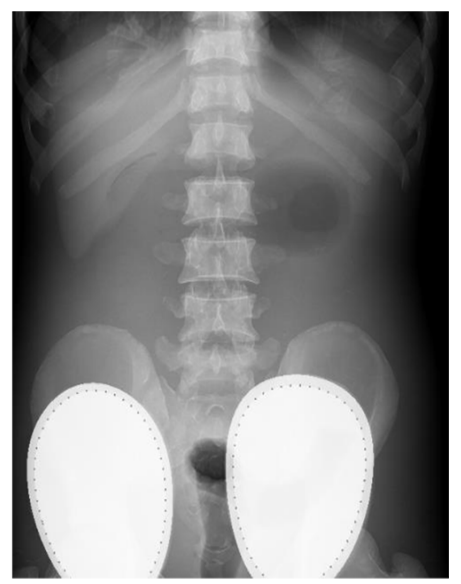

(b)

Figure 4: Comparison of abdominal images between: (a) Using $6 \mathrm{~mm}$ Silicone Rubber-Lead (SR$\mathrm{Pb})$, and (b) using lead gonad shield.

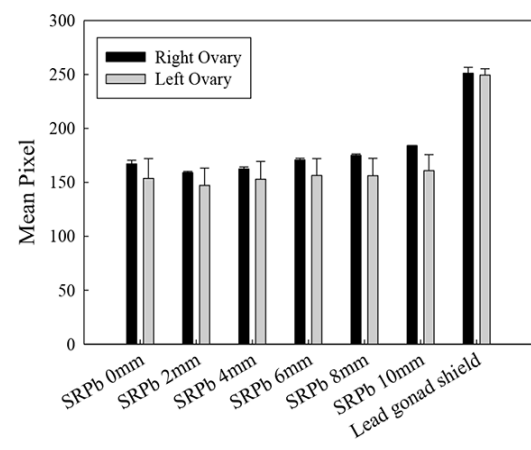

(a)

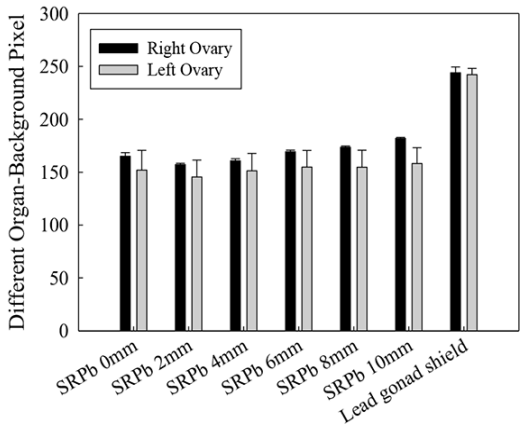

(b)

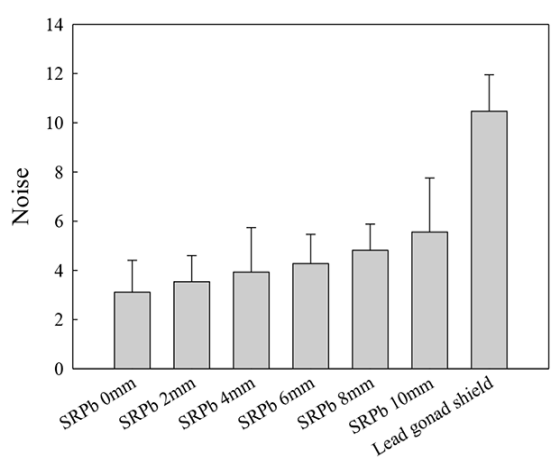

(c)

Figure 5: (a) The mean pixel value of the region of interest (ROI) (right and left ovaries) by using the Silicone Rubber-Lead (SR-Pb), (b) the different organ-background pixel value of the ROI (right and left ovaries) by using the SR-Pb, and (c) the noise value of the ROI (right and left ovaries).

5(c) shows the noise value increases with the increase of the SR-Pb thickness. The percentage of the increasing noise value was about
13.8-78.6\%. However, increases of the PV and noise in the $\mathrm{SR}-\mathrm{Pb}$ were lower than in the lead gonad shield. The mean PV, different organ- 
background pixel values, and noise value in the lead gonad shield are about 51.6, 48.59 and $236.4 \%$, respectively.

The SNR and the CNR of the image before and after using the gonad shields are depicted in the Figure 6. Figure 6(a) shows the decrease of the CNR value of the ROIs (right and left ovaries) using the lead gonad shield, and the percentage of the decreased CNR was $34.15 \%$ for the right ovary and $33.13 \%$ for the left ovary. The decreasing percentage of the CNR using the SR-Pb was about 7.14-22.2\% for the right ovary, and 9.86-29.15\% for the left ovary (Figure 6(a)). Figure 6(b) shows the decreasing SNR of the SR-Pb and the lead gonad shield. The percentage of the decreased SNR of SR$\mathrm{Pb}$ was $16.38-38.37 \%$ for the right ovary, and $15.84-41.41 \%$ for the left ovary. The CNR and SNR of the ROIs image decreased along the increasing $\mathrm{SR}-\mathrm{Pb}$ thickness. The decreasing percentage of the SNR using lead apron was about $55.32 \%$ for the right ovary, and $51.76 \%$ for the left ovary. Thus, the lead gonad shield has significantly higher values of decreasing CNR than the SR-Pb.

\section{Discussion}

This study investigated the effect of the SR$\mathrm{Pb}$ thickness as alternative gonad shields on the dose reduction and image quality in the ab- dominal examination. This study revealed that the percentage of the reduction radiation dose was $66.9 \%$ for $10 \mathrm{~mm}$ SR-Pb. Compared with the lead gonad shield, the SR-Pb performance to reduce radiation exposure was lower. Nevertheless, the SR-Pb has still had a good performance to reduce radiation exposure. The automatic exposure control (AEC) was not used in this study. Since, the combination of gonad shield with the AEC leads to uncertainty in dose reduction, i.e. it can increase or decrease dose received by patients [23].

Recently, various gonadal shields were reported. Karami et al., showed that bismuth shield can reduce the dose radiation to ovaries by $61.7 \%$ [11]. With the reduction of $66.9 \%$, it means that the dose reduction using SR-Pb is quite high; still, it can be used for clinical examination. The goal of diagnostic imaging should be obtain the diagnostic information with lowest possible radiation dose [24]. The result of the current study shows that the use of the $\mathrm{SR}-\mathrm{Pb}$ provided better image quality than the lead gonad shield. Consequently, SR$\mathrm{Pb}$ can be used as an alternative organ shield without decreasing image quality, i.e. obscuring diagnosis of abnormality. Compared to the reference image, the noise value increased with the increasing of SR-Pb thickness.

The SNR and CNR values for both ovaries

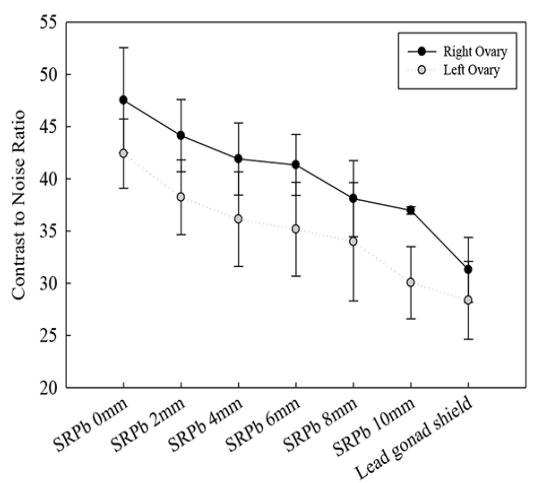

(a)

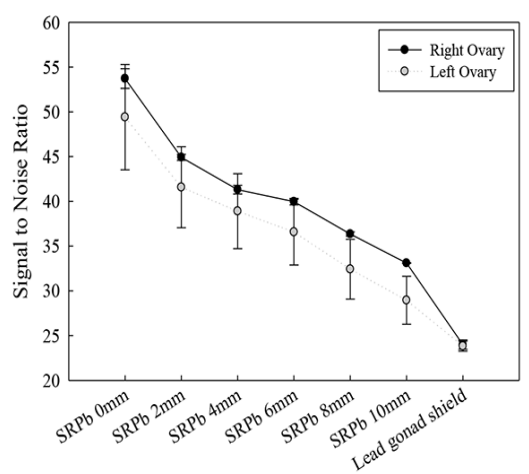

(b)

Figure 6: (a) The contrast to noise ratio (CNR) of the regions of interests (ROIs) (right and left ovaries) using the SR-Pb and lead gonad shield, and (b) the signal to noise ratio (SNR) of the ROIs (right and left ovaries) using the Silicone Rubber-Lead (SR-Pb) and lead gonad shield 
decreased with the increase thickness of the $\mathrm{SR}-\mathrm{Pb}$. It indicates that the image quality is slightly corrupted. However, the image quality of using SR-Pb compared to the lead gonad shield is significantly better. At $2 \mathrm{~mm}$, the CNR value decreased more $(7.14 \%$ for the right ovary and $9.86 \%$ for the left ovary) than the reference image. Moreover, for $6 \mathrm{~mm} \mathrm{SR-}$ $\mathrm{Pb}$, the $\mathrm{CNR}$ value decreased about $13.03 \%$ for the right ovary and $17.07 \%$ for the left ovary. The decreasing SNR value of $2 \mathrm{~mm}$ SR$\mathrm{Pb}$ was about $16.38 \%$ for the right ovary and $15.84 \%$ for the left ovary. At $6 \mathrm{~mm}$ SR-Pb, the decreasing SNR values for the right and the left ovaries were about $25.59 \%$ and $25.99 \%$, respectively.

The deficiency in our study is an existence of artifact on the images from SR-Pb with thicknesses of $8 \mathrm{~mm}$ and $10 \mathrm{~mm}$. However, the artifact is not found in the SR-Pb at $6 \mathrm{~mm}$ and less. One advantage of the $\mathrm{SR}-\mathrm{Pb}$ gonad shield is its flexibility, i.e. it follows the contour of the patient's body [14], especially in the abdomen part.

\section{Conclusion}

The $\mathrm{SR}-\mathrm{Pb}$ as a gonad shielding led to high dose reduction. The dose reduction increases with the increase of SR-Pb thickness. The maximum dose reduction was $66.9 \%$ for 10 $\mathrm{mm} \mathrm{SR}-\mathrm{Pb}$. The performance of $\mathrm{SR}-\mathrm{Pb}$ was less than lead gonad shield for dose reduction. However, SR-Pb has capability to reduce dose without significantly deteriorating the image. The image quality was maintained for the SR$\mathrm{Pb}$ compared to the lead gonad shield. The use of SR-Pb caused decrease both of CNR and SNR. The decreasing of CNR values of the $6 \mathrm{~mm}$ SR-Pb were $13.03 \%$ and $17.07 \%$, for the right and left ovaries, respectively. The decreasing of SNR values were $25.59 \%$ for the right ovary and $25.99 \%$ for the left ovary. Due to the use of lead gonad shield, the percentages of decreasing CNRs were $34.15 \%$ for the right ovary and $33.13 \%$ for the left ovary. In addition, the percentages of decreasing SNRs were $55.39 \%$ for the right ovary and $51.76 \%$ for the left ovary. However, compared to lead gonad shield, both SNR and CNR of the SR$\mathrm{Pb}$ were greater. Therefore, $\mathrm{SR}-\mathrm{Pb}$ has potential to be used as an alternative organ shield, especially as gonad shield for abdominal scan in the IVP examination.

\section{Acknowledgment}

The authors wish to thank to the Ministry of Research, Technology and Higher Education of Republic of Indonesia for supporting this work.

\section{Conflict of Interest}

None

\section{References}

1. Indonesian Ministry of Healthy. Indonesia Basic Health Research (RISKESDAS). Publication of Indonesian Ministry of Health; 2018. Available from: http://labdata.litbang.depkes.go.id/menudownload.

2. GBD Mortality and Caused of Death Collaborators. Global, regional, and national age-sex specific allcause and cause-specific mortality for 240 causes of death, 1990-2013: a systematic analysis for the Global Burden of Disease Study 2013. Lancet. 2015;385(9963):117-71. doi: 10.1016/S01406736(14)61682-2. PubMed PMID: 25530442. PubMed PMCID: PMC4340604.

3. ICRP. The 2007 Recommendations of the International Commission on Radiological Protection. Ann ICRP. 2007;37(2-4):1-332. doi: 10.1016/j. icrp.2007.10.003. PubMed PMID: 18082557.

4. Marsh RM, Silosky M. Patient Shielding in Diagnostic Imaging: Discontinuing a Legacy Practice. AJR Am J Roentgenol. 2019;212(4):755-7. doi: 10.2214/AJR.18.20508. PubMed PMID: 30673332.

5. Dauer LT, Casciotta KA, Erdi YE, Rothenberg LN. Radiation dose reduction at a price: the effectiveness of a male gonadal shield during helical CT scans. BMC Med Imaging. 2007;7:5. doi: 10.1186/1471-2342-7-5. PubMed PMID: 17367529. PubMed PMCID: PMC1831769.

6. Karami V, Zabihzadeh M, Gholami M. Gonad Shielding for Patients Undergoing Conventional Radiological Examinations: Is There Cause for 
Concern? Jentashapir J Health Res. 2016;7(2): 31170. doi: 10.17795/jjhr-31170.

7. MacKay M, Hancy C, Crowe A, D'Rozario R, Ng CKC. Attitudes of medical imaging technologists on use of gonad shielding in general radiography. Radiographer. 2012;59(2):35-39. doi: 10.1002/ j.2051-3909.2012.tb00172.x.

8. Bardo DME, Black M, Schenk K, Zaritzky MF. Location of the ovaries in girls from newborn to 18 years of age: reconsidering ovarian shielding. Pediatr Radiol. 2009;39(3):253-9. doi: 10.1007/ s00247-008-1094-4. PubMed PMID: 19130048.

9. Fawcett S, Gomez A, Barter S, Ditchfield M, Set P. More harm than good? The anatomy of misguided shielding of the ovaries. Br J Radiol. 2012;85:e4427. doi: $10.1259 / \mathrm{bjr} / 25742247$. PubMed PMID: 22096220. PubMed PMCID: PMC3587098.

10. Frantzen MJ, Robben S, Postma AA, Zoetelief J, Wildberger JE, Kemerink GJ. Gonad shielding in pediatrics pelvic radiography: Disadvantages prevail over benefit. Insights into Imaging. 2012;3(1):23-32. doi: 10.1007/s13244-011-01303. PubMed PMID: 22695996. PubMed PMCID: PMC3292647.

11. Karami V, Zabihzadeh M, Shams N, Gholami M. Radioprotection to the Gonads in Pediatric Pelvic Radiography: Effectiveness of Developed Bismuth Shield. Int J Pediatr. 2017;5(42):5153-66. doi: 10.22038/ijp.2017.23.116.1939.

12. Aral N, Nergis FB, Candan C. The X-ray attenuation and the flexural properties of lead-free coated fabrics. J Ind Text. 2016;47(2):252-68. doi: $10.1177 / 1528083716644287$.

13. Wozniak AI, Ivanov VS, Zhdanovich OA, Nazarov $\mathrm{VI}$, Yegorov AS. Modern approaches to polymer materials protecting from ionizing radiation. Oriental Journal of Chemistry. 2017;33(5):2148-63. doi: $10.13005 / 0 j c / 330502$.

14. Irdawati $Y$, Sutanto H, Anam C, Fujibuchi T, Zahroh F, Dougherty G. Development of a novel artifactfree eye shield based on silicon rubber-lead composition in the CT examination of the head. $J$ Radiol Prot. 2019;39(4):991-1005. doi: 10.1088/13616498/ab2f3e. PubMed PMID: 31272094.

15. Sutanto H, Irdawati $Y$, Anam C, Fujibuchi T, Dougherty G, Hidayanto E, Arifin Z, Soedarsono JW, Bahrudin. An artifact-free thyroid shield in CT examination: a phantom study. Biomed Phys Eng
Express. 2020;6(1):15-29. doi: 10.1088/20571976/ab6ed1.

16. Tiwari A, HiharaLH, Rawlins JW. Intelligent Coatings for Corrosion Control. Amsterdam: Elsevier; 2015. p. 585-602.

17. Davey E, England A. AP versus PA positioning in lumbar spine computed radiography: Image quality and individual organ doses. Radiography. 2015;21(2):188-96. doi: 10.1016/j. radi.2014.11.003.

18. McCaffrey JP, Shen H, Downton B, Mainegra-Hing E. Radiation attenuation by lead and nonlead materials used in radiation shielding garment. Med Phys. 2007;34(2):530-7. doi: 10.1118/1.2426404. PubMed PMID: 17388170.

19. Tsai YS, Liu YS, Chuang MT, Wang CK, Lai CS, Tsai HM, Lin CJ, Lu CH. Shielding during x-ray examination of pediatric female patients with developmental dysplasia of the hip. $J$ Radiol Prot. 2014;34(4):801-10. doi: 10.1088/09524746/34/4/801. PubMed PMID: 25325378.

20. Jang JS, Yang HJ, Koo HJ, Kim SH, Park CR, Yoon SH, Shin SY, Do KH. Image quality assessment with dose reduction using high $\mathrm{kVp}$ and additional filtration for abdominal digital radiography. Physica Medica. 2018;50:46-51. doi: 10.1016/j. ejmp.2018.05.007. PubMed PMID: 29891093.

21. Hess R, Neitzel U. Optimizing Image Quality and Dose for Digital Radiography of Distal Pediatric Extremities Using the Contrast-to-Noise Ratio. Fortschr Röntgenstr. 2012;184(7):643-9. doi: 10.1055/s-0032-1312727. PubMed PMID: 22618480.

22. Mraity HAAB, England A, Cassidy S, Eachus $P$, Dominguez A, Hogg P. Development and validation of a visual grading scale for assessing image quality of AP pelvis radiographic images. Br J Radiol. 2016;89(1061):1-27. doi: 10.1259/ bjr.20150430. PubMed PMID: 26943836. PubMed PMCID: PMC4985444.

23. Kaplan SL, Magill D, Felice MA, Xiao R, Ali S, Zhu $X$. Female gonadal shielding with automatic exposure control increases radiation risks. Pediatr Radiol. 2018;48:227-34. doi: 10.1007/s00247017-3996-5.

24. AAPM. Protocol for the radiation safety surveys of diagnostic radiological equipment. New York: Inc. Report no 25; 1988. 